\title{
Evaluating Adaptive Navigation Support
}

Kristina Höök

HUMLE, SICS

Box 1263, S-164 29 Kista, Sweden

kia@sics.se, http://www.sics.se/ kia/

\section{INTRODUCTION}

"Lost in hyperspace" is a feeling that is familiar to almost anyone using a computer. After a few actions, we do not know where we are, how we got there, or what our original goal was. Adaptive navigation systems has been proposed as a means to aid users in finding their way through information spaces. Several systems have been designed that adapts the navigation to users' knowledge (e.g 11), to users' preferences and goals (9), to users' tasks (8), or to users' spatial ability $(1,6)$. The hope is that if user characteristics are considered the cognitive workload can be reduced, or users' learning may be improved, etc., but will they?

\section{Keywords}

Adaptive, navigation, evaluation, hypermedia

\section{EVALUATIONS OF ADAPTIVE NAVIGATION SYSTEMS}

From the few evaluations of adaptive navigation systems that have been performed $(2,3,4,5,7,8,9,10,12)$, we see an emerging pattern where depending upon the domain, only certain types of adaptive navigation strategies work. Adaptations should leave the interface somewhat predictable so that users do not feel lost, not force users to interpret advanced annotations, thus distracting them from their main tasks, and the adaptive navigation support should not change the structure of the space.

This of course depends upon the domain, users, and their tasks. For example, in a large domain that users seldom revisit and where there is no need for the user to learn the structure of the space, adaptive guidance might be very useful. Also, in a domain where the structure is of (nearly) no importance, as for example, in a collection of movies or food recipes, where any organisation can work, adaptation as a means of structuring the space according to preferences may work really well (see e.g. (11)). In a domain to which users frequently return and where shortcuts are useful, adaptations based on interactions with the users might be useful (as in (10)).

Unfortunately evaluations of adaptive navigation support systems fail to recognise some of the more important aspects of why certain systems provide better support than

\section{LEAVE BLANK THE LAST $2.5 \mathrm{~cm}$ (1") OF THE LEFT COLUMN ON THE FIRST PAGE FOR THE COPY- RIGHT NOTICE.}

\author{
Martin Svensson \\ DSV, Stockholm University/KTH \\ Electrum 230, 16440 Kista, Sweden \\ martins@sics.se, http://www.sics.se/ martins/
}

others do. These studies typically measure task completion time, or how well the structure of the space is remembered. While these are among the important measurements that should be taken, other features, such as how much anxiety the system induces in users, how pleasant it is to navigate, or how much users actually learn of the information contained in the space, might be more crucial measurements.

\section{REFERENCES}

1. Benyon, David R., and Murray, Diane (1993). Developing Adaptive Systems to Fit Individual Aptitudes, In W.D. Gray, W. E., Helfley and Murray, D. (eds.), Proceedings of the 1993 International Workshop on Intelligent User Interfaces, Orlando, FL., New York, ACM Press.

2. Boyle, C., and Encarnacion, A. O. (1994). MetaDoc: An Adaptive Hypertext Reading System, User Models and User Adapted Interaction, (UMUAI) 4, pp. 1 - 19.

3. Brusilovsky, P. and Pesin, L. (1994). ISIS-Tutor: An adaptive hypertext learning environment In H. Ueono \& V. Stefanuk (eds.), Proceedings of JCKBSE'94, Japanese-CIS Symposium on knowledgebased software engineering, Tokyo: EIC.

4. Brusilovsky, P., and Schwartz, E. (1997). User as Student: Towards an Adaptive Interface for Advanced Web-Based Applications, User Modeling, Proceedings of the Sixth International Conference, UM97, A. Jameson, C. Paris, and C. Tasso (eds.), CISM 383, Springer.

5. Carter, E. (1996). Quantitative Evaluation of Hypertext: Generation and Organisation Techniques, Ph.D. thesis, University of Edinburgh.

6. Dahlbäck, N., Höök, K. and Sjölinder, M. (1996). Spatial Cognition in the Mind and in the World: The case of hypermedia navigation, The Eighteenth Annual Meeting of the Cognitive Science Society, CogSci'96, University of California, San Diego.

7. Eklund, J., Brusilovsky, P., and Schwartz, E. (1998a) A study of adaptive link annotation in educational hypermedia, EdMedia98, Freiburg, Germany.

8. Eklund, J., and Brusilovsky, P. (1998b). The Value of Adaptivity in Hypermedia Learning Environments: A Short Review of Empirical Evidence. 2nd Workshop on Adaptive Hypertext and Hypermedia HYPERTEXT'98, Pittsburgh, USA.

9. Höök, K. (1998), Evaluating the Utility and Usability of an Adaptive Hypermedia System, in Journal of Knowledge-Based Systems, vol. 10, no. 5, 1998 .

10. Kaplan, C., J. Fenwick and J. Chen. (1993). Adaptive Hypertext Navigation Based On User Goals and Context, User Modeling and User-Adapted Interaction 3, pages 193-220.

11. Shardanand, U and Maes, P (1995). Social Information Filtering: Algorithms for Automating 'Word of Mouth'. Proc. Human factors in computing systems '95, Denver, CO, ACM Press, pp. 210-217.

12. Weber, G., and Specht, M. (1997). "User Modeling and Adaptive Navigation Support in WWW-Based Tutoring Systems", User Modeling, Proceedings of the Sixth International Conference, UM97, A. Jameson, C. Paris, and C. Tasso (eds.), CISM 383, Springer. 